\section{Personalzeiten, direkte}

C. Vidal ${ }^{1}$ und W.-R. Külpmann ${ }^{2}$

${ }^{1}$ Landeskriminalamt Niedersachsen, Dezernat 53 „Chemie“, Hannover, Deutschland

${ }^{2}$ Hannover, Deutschland

Definition Die für die Durchführung einer Einzelanalyse von einer Person tatsächlich benötigte Zeit.
Beschreibung Die direkte Personalzeit umfasst nicht die Standzeiten (z. B. Zentrifugieren, Inkubation). Kurze Wartezeiten, in denen andere Tätigkeiten nicht möglich sind, zählen jedoch zur direkten Personalzeit.

\section{Literatur}

Haeckel R, Fischer G, Fischer M et al (1984) Vorschläge zur Definition von Zeitbegriffen. Dt Ges Klin Chem Mitteilungen 14:187-192 